\title{
Research on RMB Exchange Rate Fluctuation Considering Effect of Central Parity
}

\author{
Zeyang Rong ${ }^{1, a}$ \\ ${ }^{1}$ School of Banking \& Finance, University of International Business and Economics, Beijing, 100029, China
}

Keywords: Central parity, RMB, Exchange rate

\begin{abstract}
This paper collected the historical data of the central parity of RMB/ dollar from June 19, 2010 to February 17, 2015. Through the mathematical model, the existing problems of the exchange rate of $\mathrm{RMB}$, and the features of financial market centralization, continuity and discontinuity were studied in the paper. At present, the central bank's control over the exchange rate is effective. But we should cope with the appreciation of the RMB through the control of foreign currencies. The focus of monetary management in China should be the control of the exchange rate of RMB, so as to meet the needs of social development.
\end{abstract}

\section{Introduction}

The control of RMB is one of the most important issues in our society. The United States and Japan have put pressure on our government to manipulate the RMB exchange rate for a long term. With the deepening of China's reform and opening, the RMB exchange rate control system is gradually improved, which can meet the needs of changes in the situation at home and abroad. With the transformation of China's economy has entered a new norm, the RMB exchange rate changes, is entering a new development cycle, from fluctuations in the trend, showing a two-way fluctuations in the RMB exchange rate flexibility in the form of currency changes, reflected, in this case, the central parity of RMB exchange rate for RMB appreciation plays a very important role to the economic, many scholars hope to reflect the current situation through the middle price of the RMB exchange rate appreciations. Through the analysis of the latest data of price fluctuations of RMB, the paper verified the effect of the policy of China's central bank and the Volatility theory.

\section{Research of Current Theories}

In the past long period of time, China's monetary and exchange rate policy reform is not continuous, while the RMB is on the rise in general. Therefore, in the early stage of the RMB exchange rate is difficult to statistics, analysis of the existence of certain problems, in time, it does not have stability, or constraints are poor, difficult to collect. After China's entry into the new economic norm, the change of the RMB exchange rate is becoming more and more inconsistent with the model set up at the beginning, so it is necessary to analyze it again. At the same time, the international government has criticized the Chinese government's policy on exchange rate. In bilateral talks, China has a negative attitude towards the manipulation of the RMB exchange rate. The latest data changes are of vital importance for the development of the renminbi. Therefore, it is necessary for us to collect and analyze the data again.

\section{Empirical Analysis}

This paper chooses the GARCH model to study the historical data of RMB exchange rate in recent years, the quantitative analysis of agglomeration, persistence and asymmetry of the RMB exchange rate fluctuations, and compare it with the existing results to explain the reason for the change.

Data Sources. The data comes from the State Administration of foreign exchange on the official website from the June 19, 2010 to February 17, 2015 (after the international financial crisis China's 
resumption of the reform on the 2015 Spring Festival), including each trading day of the RMB / dollar exchange rate time series data (RMBE), a total of 1132 data samples. The data processing software used in this article is Eviews6.0. It can be found that the RMBE time series has a spike thick tail feature and does not obey the normal distribution.

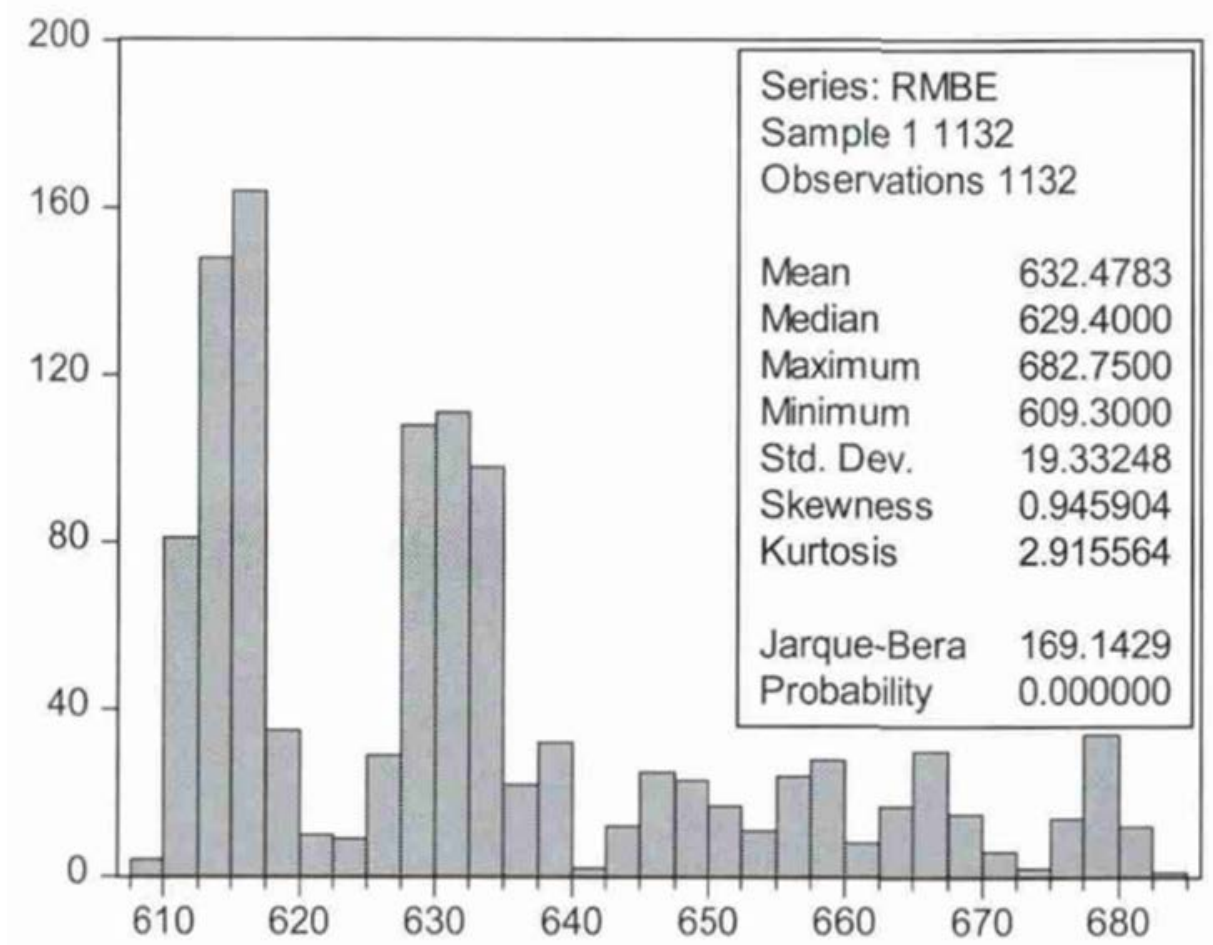

\section{Model Estimation.}

Figure 1. Unnormal distribution of RMBE time series

Stationarity test. Time series analysis needs to test the stationarity of time series data. The ADF unit root test is used in this paper. The test results are shown in figure 2 . The results show that there is a unit root in the RMBE sequence at $5 \%$ and below, so a lag first order regression model should be established.

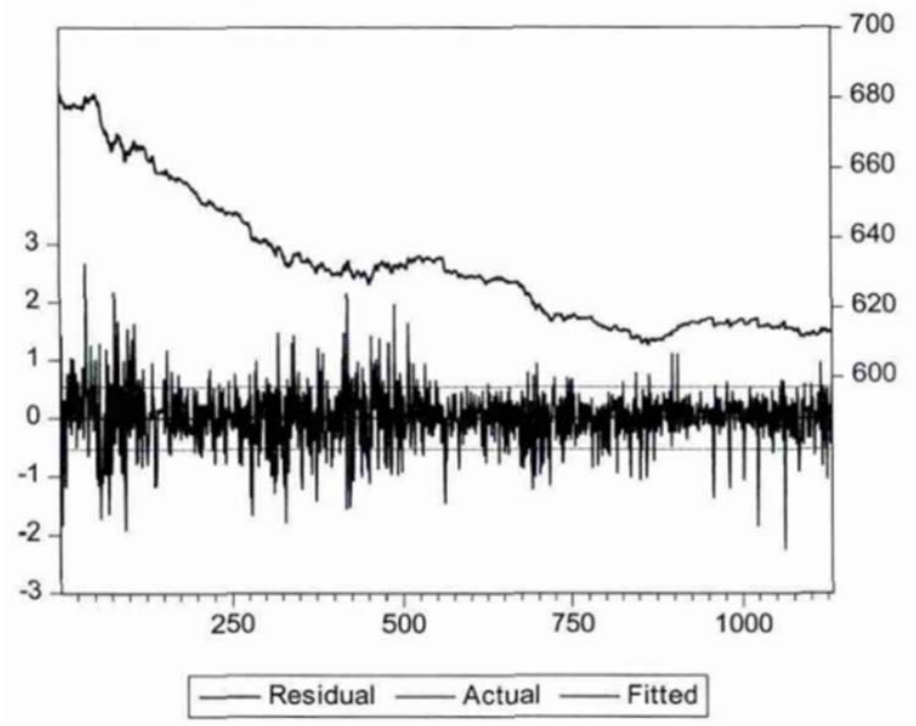

0 RMBE

Figure 2. Stationarity test result 
Table 1. Test form, t statistics and adjoin probability

\begin{tabular}{|c|c|c|}
\hline $\mathrm{N}$ & $\mathrm{RMBE}$ & $\mathrm{ADF}$ \\
\hline Test form & $\mathrm{t}$ statistics & Adjoint probability \\
\hline$(\mathrm{c}, 0,0)$ & -2.8603 & 0.0505 \\
\hline$(\mathrm{c}, \mathrm{t}, 0)$ & -1.854611 & 0.6772 \\
\hline$(0,0,0)$ & -3.613665 & 0.0003 \\
\hline$(\mathrm{c}, 0,1)$ & -31.18181 & 0 \\
\hline$(\mathrm{c}, \mathrm{t}, 1)$ & -31.32963 & 0 \\
\hline$(0,0,1)$ & -30.8217 & 0 \\
\hline
\end{tabular}

Mean model. According to the result of unit root test, the following mean equation of the first order lag regression is established.

$$
\begin{gathered}
\mathrm{RMBE}=0.997053 \mathrm{RMBE}(-1)+1.802770 \\
(1208.566) \quad(3.453287) \\
\mathrm{R} 2=0.999228, \bar{R} 2=0.999227, \quad \text { D.W. }=1.852537
\end{gathered}
$$

GARCH $(1,1)$ model established. The result is: RMBE=0.997229RMBE $(-1)+1.686333$

The perturbation of conditional variance is persistent and slowly attenuated. Once again, the residual is tested by ARCH, and the test results indicate that there is no ARCH effect.

TARCH $(1,1)$ model. In addition, TARCH $(1,1)$ model can be established to obtain the equation of variance. The RMB exchange rate has a leverage effect is obvious, mainly reflected in its asymmetry. At the same time of the appreciation of the renminbi, the impact is large and the devaluation of the impact of small. That is to say, the negative impact has a more important role for the exchange rate the volatility of the RMB, but the leverage effect of volatility is smaller.

Comparison and explanation of research results. In the literature review, we have collated and analyzed the exchange rate of RMB. Some of these data are inconsistent with each other, so they need to be eliminated. In previous studies, many papers established GRACH models, and the constraints were not clear. This is not successful enough, because they mainly use the RMB data before 2010, but at this stage, China has carried out the economic new normal and camp reform and other policy reforms. Therefore, the model cannot meet the needs of China's current exchange rate development, and at the same time, the market level of China's RMB exchange rate is constantly improving, which has been reflected in the latest data. In this paper, the re-establishment of this model is to make a realistic analysis of the current reform of the RMB exchange rate, because the policy of the central parity is becoming mature, and the volatility becomes larger. However, with China's reform on exchange rate policy, is conducive to the promotion of the market mechanism of the RMB exchange rate is more mature. We must deal with the international society of RMB exchange rate volatility, and the RMB value is more stable.

On the other hand, compared with the previous research results, through the quantitative analysis, we can see that the same compared to them, after the start of China's reform of the exchange rate policy, to the financial risk response plan in the world increased significantly, with the ability to significantly enhance, the central parity of RMB exchange rate fluctuations cycle is shortened in the constraint conditions, and at the same time for the existing achievements and we can see that the RMB exchange rate fluctuations can last for a long time, because China's RMB exchange rate control is limited. The kind of restrictions lead to expectations of RMB in the past foreign market appreciation has been the existence of a high pressure. The calm with the volatility of the RMB the exchange rate has been expanding some relief, but it does not fundamentally solve the fluctuation problem of RMB exchange rate.

From the existing research results, we find the exchange rate has a very important practical significance, the symmetry and asymmetry is mainly manifested in the RMB exchange rate 
fluctuations, which shows in 2005 after a new round of monetary policy and exchange rate policy reform, more on the impact of the RMB appreciation, the smaller the impact of devaluation. At the same time, it can be seen from the literature that whatever model is adopted, the analysis of the RMB exchange rate can lead to similar asymmetric conclusions. The RMB exchange rate is rising overall, but its impact on the appreciation of the effect is significantly greater than its devaluation. The main reason is that our country in the past for a long period of time is relatively rapid economic growth and the expectations of the market and the government is expected to be consistent with the new normal, after China's entry into the economy, the RMB exchange rate is adjusted, the RMB exchange rate in the foreign exchange market appeared floating on, but this is not a small floating to change, the non-symmetry characteristics of the reform of the RMB exchange rate policy, to leverage its before weakening, which is conducive to China's use of the renminbi in international market to help to break the Bretton forest system.

\section{Conclusions}

In this paper, the mathematical model is established to study and verify the volatility and sustainability of the RMB exchange rate fluctuation. It is found that the asymmetry is weakening and the leverage effect is obviously decreasing. Through empirical analysis, we can point out that the RMB exchange rate reform after the international financial crisis has significantly improved its property in the financial market.

In this paper, through empirical analysis, we can see that China's exchange rate reform has made great achievements, China's long-term RMB exchange rate reform, expand the fluctuation of RMB exchange rate, the RMB exchange rate elasticity of growth, have a positive significance. Experienced in banking and financial markets and long-term experience in risk aversion. Through the construction of good credit evaluation system and the regular maintenance of customer information, customer information verifies the internet and many other ways to update, for each customer and potential customer's credit rating, and do a good job of risk prevention measures.

This paper puts forward some suggestions for the development of China's foreign exchange market. First, we should relax restrictions on entry into the foreign exchange market. In addition to some capital accounts, foreign exchange trading should be adjusted with the RMB exchange policy. Second, should increase foreign exchange market, so that more companies can participate in the foreign exchange market, to control the RMB exchange rate. It is conducive to establish more mature risk coping strategies to prevent the more serious situation of the exchange rate volatility.

Of course, this paper also has the following limitations: (1) we select the central parity of RMB / dollar, ignoring the effective exchange rate and exchange rate. However, it is permitted in the empirical analysis, and is subject to the purpose of this study; (2) this paper carries on the analysis to the RMB each trading day wave and fails to reveal the impact of RMB exchange rate changes; (3) the relationship of RMB exchange rate volatility and market expectations have not been in-depth analysis; (4) the effect of our central bank of thousands of RMB exchange rate is studies. These objectives are related to the study of this paper, but not the objective of this study, which needs to be completed in other future research.

\section{References}

[1] Cui Baisheng. A Positive Analysis of RMB Exchange Rates Based on the Pair Copula-GARCH-t Model [J].Journal of Shanghai Normal University(Philosophy \& Social Sciences Edition), 2011, 40(3): 32-43.

[2] Wu Meiqiu. On the Exchange Rates Fluctuation Trend of the Dollar against the RMB: Based on the GARCH Model [J]. Journal of Tongling University, 2016(6): 27-30+55.

[3] Ye Yafei, Shi Jianxun. Research on the Market Pricing of RMB Exchange RateAn empirical Analysis Based on DCC- GARCH Model [J]. Shanghai Journal of Economics, 2016(6): 36-42+52. 
[4] Guan Shan, Zhu Jiaming. Study of RMB Exchange Rate Volatility Based on GARCH Model [J]. Journal of Shanghai University of Engineering Science, 2017, 31(1): 84-89. 